\title{
Preparing for Renovation: Estimating Shelf Occupancy to Inform Decision Making Regarding the Redevelopment of Library Space
}

\author{
William H. Weare Jr., Texas A\&M University, College Station, Texas
}

Paul Moffett \& John P. Cooper, Indiana University-Purdue University Indianapolis, Indianapolis, Indiana

\begin{abstract}
University Library at Indiana University-Purdue University Indianapolis is in the process of repurposing space currently occupied by the print collection. To prepare for further reallocation of library space, reliable estimates of stacks space were needed. Two members of the Access Services Team applied systematic random sampling to estimate existing-and anticipated-empty shelf space. Results indicate that more than $30 \%$ of the shelf space is empty, while over $25 \%$ is occupied by journals, most of which are available in electronic format. These estimates would be used to inform decision making about shifting and/or withdrawal of library materials in preparation for the renovation of additional library spaces. The data-gathering process as well as data analysis and application used during the project may be applicable in other academic libraries.
\end{abstract}

\section{Keywords}

Data collection methods; library planning; library renovation; reallocation of space; space utilization; stacks measurement; systematic random sampling 


\section{Introduction}

In recent years there has been a thoughtful discussion in the library literature regarding the changing nature of library space. Forward-thinking librarians have raised questions about how space is being used now and how it might be redeveloped to better meet the current and future needs and expectations of library users (Allan 2013; Bulpitt 2013; Dewey 2008; Gayton 2008; Lewis 2007; Maxymuk 2010; Robinson 2009; Simon 2013). Writing about changes in collection practices, Lewis (2013) suggested, "By the early 2020s, it is easy to imagine the following: Print collections will have been reduced by at least half in most academic libraries. The space will be used for a combination of enhanced reader spaces and other activities" (172).

Reflecting this trend, David Lewis, dean of the Indiana University-Purdue University Indianapolis (IUPUI) University Library, has directed several initiatives during the past decade to renovate a number of spaces in the library. Anticipating that over the next several years more space currently occupied by the stacks will be repurposed for uses other than housing materials, he requested that the Access Services Team provide an estimate of available shelf space, a figure that would allow him to gauge the square footage available for potential renovation projects. Recognizing this need for up-to-date and accurate data about the book stacks, the staff sought a simple, quick, and efficient method of measuring occupied, available, and potentially available shelf space to facilitate informed decision making prior to the shifting and/or withdrawal of materials.

\section{Factors driving renovation}

Renovation of library space has been motivated by three main developments. First, as noted by Dewey (2008), the primary driver has been the shift from print to digital access (86). Statistics collected at IUPUI University Library indicate that for journals, this could be a significant source of space. An annual count of journal use at IUPUI University Library since 1998/99 indicates a significant decline in 
the use of print journals. In addition to the decline in use, Cooper, an IUPUI staff member, reported that "over two-thirds of the titles that were in the journal use study during the 2000/01 fiscal year were no longer available to our patrons in print by the end of the 2009/10 fiscal year. The greatest number of these titles was switched from print to online only" $(2011,44)$. Second, there have been considerable changes in the types of learning activities students engage in, and so their needs and their expectations of the library have changed significantly. Students request comfortable, lively, and active spaces where they can interact with each other and with information and with technology (Lewis 2007). Students choose libraries as their study place to be with a community of learners and feel a sense of common identity (Bulpitt 2013; Allan 2013). Third, a shortage of campus space, coupled with a willingness on the part of library administrators to form partnerships across campus, has resulted in more campus units, such as writing centers, being housed in the library. Robinson (2009) wrote, "The institutional need for space will trump "dusty stacks," especially given the ubiquitous online access to information resources" (6).

These factors have contributed to decisions about renovation at University Library at IUPUI. A review of the library literature (below) yielded a rich variety of alternative uses for stacks space but relatively few methods of measurement. Those uncovered seemed more complex than needed at IUPUI, so two staff members applied a simpler method to estimate shelf capacity. In this article, the authors describe the data-gathering process and analysis during the project which may be applicable in other academic libraries.

\section{IUPUI University Library background}

Founded in 1969, IUPUI was formed as a partnership between Indiana University and Purdue University. Today the IUPUI campus hosts twenty-one schools with academic units granting degrees in more than 250 programs from both Indiana University and Purdue University. Home to nationally

This is an electronic version of the following article: Weare, W. H., Jr., Moffett, P., \& Cooper, J. P. (2016). Preparing for renovation: Estimating shelf occupancy to inform decision making regarding the redevelopment of library space. Collection Management, 41(3), 168-181. Collection Management is available online at: 
ranked programs in health, law, nursing, and public and environmental affairs, IUPUI enrolls more than 22,000 undergraduate and 8,200 graduate and professional students.

University Library, completed in 1993, serves all undergraduate, graduate, and professional programs except law, dentistry, and medicine, which are served by their own libraries. The library has a national reputation for developing innovative learning and study spaces incorporating leading-edge technology and is the top student destination on campus for study, collaborative work, and access to emerging information technologies. It has five floors, contains more than a quarter of a million square feet of usable space, houses 1.2 million volumes, and provides access to more than 80,000 electronic serial titles, thousands of e-books, and hundreds of databases. As is true in many research libraries, the status of the print collection at the University Library is in flux. Although the library maintains few current print journal subscriptions, large runs of bound journals and printed indexes continue to be housed in the collection. Recently 50,000 low-use monographs ( $8.5 \%$ of the collection) were withdrawn as they are held at other in-state libraries, but University Library still has a significant print book collection.

\section{Motivation}

Unlike many academic libraries, University Library continues to have adequate space to accommodate collection growth. This does not mean, however, that the use of space is not an important consideration. Members of the library's leadership team have decided that there are better uses for space occupied by the stacks than storing seldom-used monographic titles and print journals with content now available electronically. The library currently houses more than a dozen tenantscampus units that do not report to the Dean of University Library-including the Arts and Humanities Institute, the Honors College, the Center for Teaching \& Learning, the Office of the Vice Chancellor for Research, and the Department of Journalism and Public Relations. It is widely expected that the building

This is an electronic version of the following article: Weare, W. H., Jr., Moffett, P., \& Cooper, J. P. (2016). Preparing for renovation: Estimating shelf occupancy to inform decision making regarding the redevelopment of library space. Collection Management, 41(3), 168-181. Collection Management is available online at: 
will be accommodating other campus units in the near future. To facilitate shifts of the collection to make room for other units, or individual or collaborative student study spaces, it will be necessary to determine how much empty shelf space is available in the stacks.

Following the dean's initial inquiry, those members of the Access Services Team working on the project formulated two questions regarding occupied, available, and potentially available shelf space.

First, we needed to know how much empty shelf space currently existed. Second, we were interested in how much shelf space would become available if printed indexes and journals (now available electronically) were to be withdrawn. This does not necessarily mean all indexes or all journals would be withdrawn or relocated, but these estimates may prove useful to library liaisons who make decisions as to which would remain in the collection. Our intention is to provide a general estimate of current space allocation, not to make specific recommendations regarding titles.

In order to answer the dean's initial query as well as our own questions, we needed an accurate and efficient method for measuring existing and anticipated shelf space. Having determined that the methods described in the literature were not suitable for our needs, two staff members, Moffett and Cooper, implemented a relatively simple method of sampling shelf occupancy. Once the data were gathered, the dean could convert the estimates of available space into estimates of square footage.

\section{Literature review}

A search of the library literature has shown that concerns about running out of space for collections in academic libraries dates to the early 1970s. In an effort to address concerns about the library at the University of Newcastle upon Tyne reaching "complete fullness," Balmforth (1973) described the planning and preparation necessary to assess stacks capacity, including a volume count and the measurement of both occupied and unoccupied shelf space. Daehn (1982) described "a shelf space and stack capacity assessment" (28) at the University of Guelph Library. Babits and Grice (1987)

This is an electronic version of the following article: Weare, W. H., Jr., Moffett, P., \& Cooper, J. P. (2016). Preparing for renovation: Estimating shelf occupancy to inform decision making regarding the redevelopment of library space. Collection Management, 41(3), 168-181. Collection Management is available online at: http://tandfonline.com/toc/wcol20/41/3?nav=tocList. 
addressed concerns about space limitations at Union College in Schenectady, New York. Davis (1987) described space problems and solutions at two public libraries in lowa. Concerns about running out of space continued to appear in the library literature during the 1990s (Gyeszly, Bustion, and Treadwell 1990; Sapp and Suttle 1994; Wallace 1990). Wallace (1990) described a method used to measure the current collection and the approach employed to calculate projections of future growth. Sapp and Suttle (1994) provided a detailed description of the methods used to measure occupied and available shelf space as well as to estimate the annual rate of collection growth at Montana State University.

Many libraries still confront shortages of space in which to house growing collections despite years of tight budgets (resulting in slowed growth for some libraries) and the shift from print to electronic access. A variety of approaches have been used to address this challenge. Some libraries installed compact shelving, built or purchased off-site storage facilities, or, when constructing new libraries, incorporated high-density automated storage and retrieval systems. Case studies describing how individual libraries have responded to the increasing space pressures continued to appear in the literature (Case and Ingram 2006; Castro 2011; Cooper and Norris 2007; Kaplan, Steinberg, and Doucette 2006; Sharp 2009). In addition to noting a lack of growth space for collections, Kaplan et al. (2006) also pointed out the "need to provide new additional multiuse environments" (387). Only two recent cases described procedures for measuring available shelf space (Case and Ingram 2006; Castro 2011).

The rationale for measuring occupied, available, and potentially available shelf space has largely changed, but the need to do so remains. A review of case studies in the current literature shows that space for new endeavors is found almost exclusively through the relocation or withdrawal of print journals (Cooper and Norris 2007; Griffin and Foret 2011; Persily and Butter 2010; Robinson 2009; Thomas and Shouse 2012). Put simply, Lewis (2013) pointed out that "journals will be the easiest places to begin" (169).

This is an electronic version of the following article: Weare, W. H., Jr., Moffett, P., \& Cooper, J. P. (2016). Preparing for renovation: Estimating shelf occupancy to inform decision making regarding the redevelopment of library space. Collection Management, 41(3), 168-181. Collection Management is available online at: 
The methods used to measure shelf space described in the literature have tended to be complex. With the advent of increasingly user-friendly and affordable computers in the 1980 s, librarians began to employ software to create spreadsheets to track occupied shelf space, determine available shelf space, and (in some cases) project future growth (Babits and Grice 1987; Desroches and Rudd 1983; Moreland 1987; Peacock 1983; Peacock 1985; Smith 1990; Wallace 1990). In the 1980s, the use of computers to do this kind of work was innovative, although complicated. For example, Peacock (1983) described a process in which all 16,000 shelves in Stirling University Library (United Kingdom) were inspected and an estimate was made as to whether each shelf was full, three-quarters full, half full, onequarter full, or empty (152). Smith (1990) described the procedure used for measuring and recording the shelving capacity and physical arrangement of the collection at University College, Cardiff (United Kingdom), which included the drawing of a master plan of each alcove and range, the measurement of the width and height of each section, and the measurement and recording of occupied shelf space "in millimeters, to the nearest half centimeter" (66-67). In addition, every range and every section was assigned an alphanumeric code resulting in a unique identifier for every shelf. Several methods described in the literature involved the creation or use of floor plans, a master plan, or stacks blueprints as a part of the collection measurement process (Castro 2011; Montanelli 1987, Smith 1990; Smith 2007).

More recent articles-though no longer quite so enamored of the options made possible by computers-continue to describe methods of managing shelf space that are no less time-consuming and complex (Case and Ingram 2006; Castro 2011; Cooper and Norris 2007). The shelf measurement process described in these articles did not align with the needs of our project because it did not call for this level of complexity. We sought an alternative and we instead implemented a quick and simple method that was more appropriate for our needs.

This is an electronic version of the following article: Weare, W. H., Jr., Moffett, P., \& Cooper, J. P. (2016). Preparing for renovation: Estimating shelf occupancy to inform decision making regarding the redevelopment of library space. Collection Management, 41(3), 168-181. Collection Management is available online at: http://tandfonline.com/toc/wcol20/41/3?nav=tocList. 


\section{Data gathering and processing}

At University Library we identified several desired outcomes for the measurement project. Our primary objective was to estimate the amount of empty shelf space currently available. Our secondary objective was to identify additional areas currently occupied by the stacks that could become available if certain types of materials were withdrawn. The library continues to house print indexes that are available electronically, such as Biological Abstracts, Chemical Abstracts, and Mathematical Reviews. Even more space could be made available by the withdrawal of print journals now available through electronic journal subscription, aggregate databases, or JSTOR.

Having considered a number of possible approaches for measuring the current and available shelf space, the authors met with Dean Lewis to discuss strategies for this project. He suggested that applying a sampling method would be the most efficient approach. Therefore, we employed a systematic random sampling method in which the researcher selects every nth unit (Beck and Manuel 2008). In this case, the nth unit was the middle shelf of every fifth section.

\section{The collection}

The main print collection is housed on the third and fourth floors of University Library. Each floor houses ten blocks of shelving; a block comprises six to sixteen ranges of shelving. AC to BV and BX to $\mathrm{E}$ are examples of a block (see Figure 1). Materials classed $\mathrm{A}$ through $\mathrm{N}$, containing subjects in the social sciences and humanities, are housed on the third floor. The fourth floor ( $\mathrm{P}-\mathrm{Z}$ ) houses mostly physical and applied sciences. The length of ranges within each block varies by location; some comprise fourteen sections and others fifteen. Each section is either thirty or thirty-six inches wide. Shelf height within each section is adjustable, and sections have either five, six, or seven shelves each, depending upon the height of materials on the shelves. In order to account for differing shelf lengths and the 
varying numbers of shelves within a section, all measurements were recorded in inches rather than shelves or portions of a shelf.

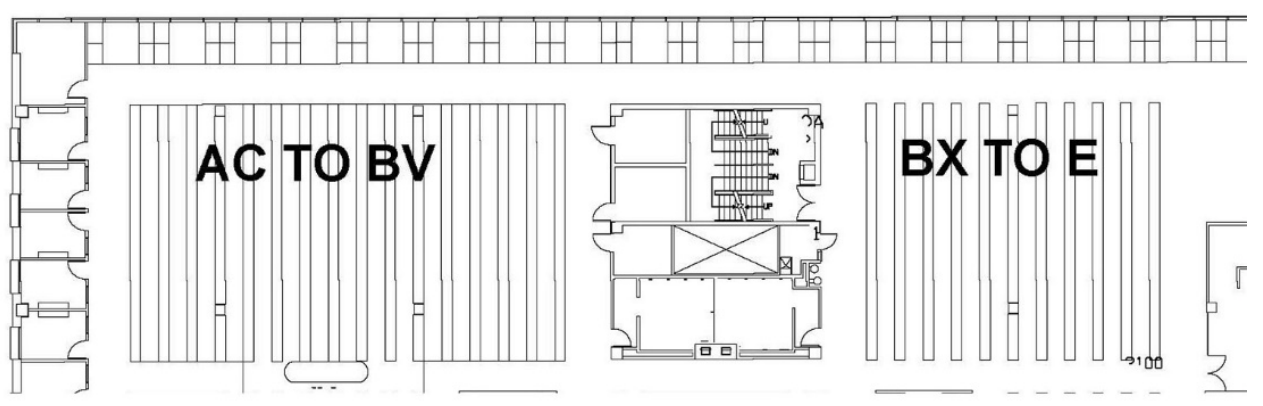

Figure 1. Example of call number classes extended over block layout.

\section{The measurement process}

We created a form in a Microsoft Excel spreadsheet to capture the following data: length of the sample shelf, number of inches occupied by monographs, inches occupied by journals, and inches of unoccupied space (see Figure 2). (At University Library, journals and books are interfiled in one call number sequence.) Although tedious, the measurement process was not time-consuming. Two access services staff members worked two hours per day, two or three times per week, to take measurements from sample sections over the course of six weeks. They measured 1,070 out of 34,858 shelves, or approximately $3 \%$ of the total. The data were used to calculate estimates of the percentage of shelving occupied by monographs, percentage of shelving occupied by journals, and the percentage of empty space on each shelf.

This is an electronic version of the following article: Weare, W. H., Jr., Moffett, P., \& Cooper, J. P. (2016). Preparing for renovation: Estimating shelf occupancy to inform decision making regarding the redevelopment of library space. Collection Management, 41(3), 168-181. Collection Management is available online at: http://tandfonline.com/toc/wcol20/41/3?nav=tocList. 


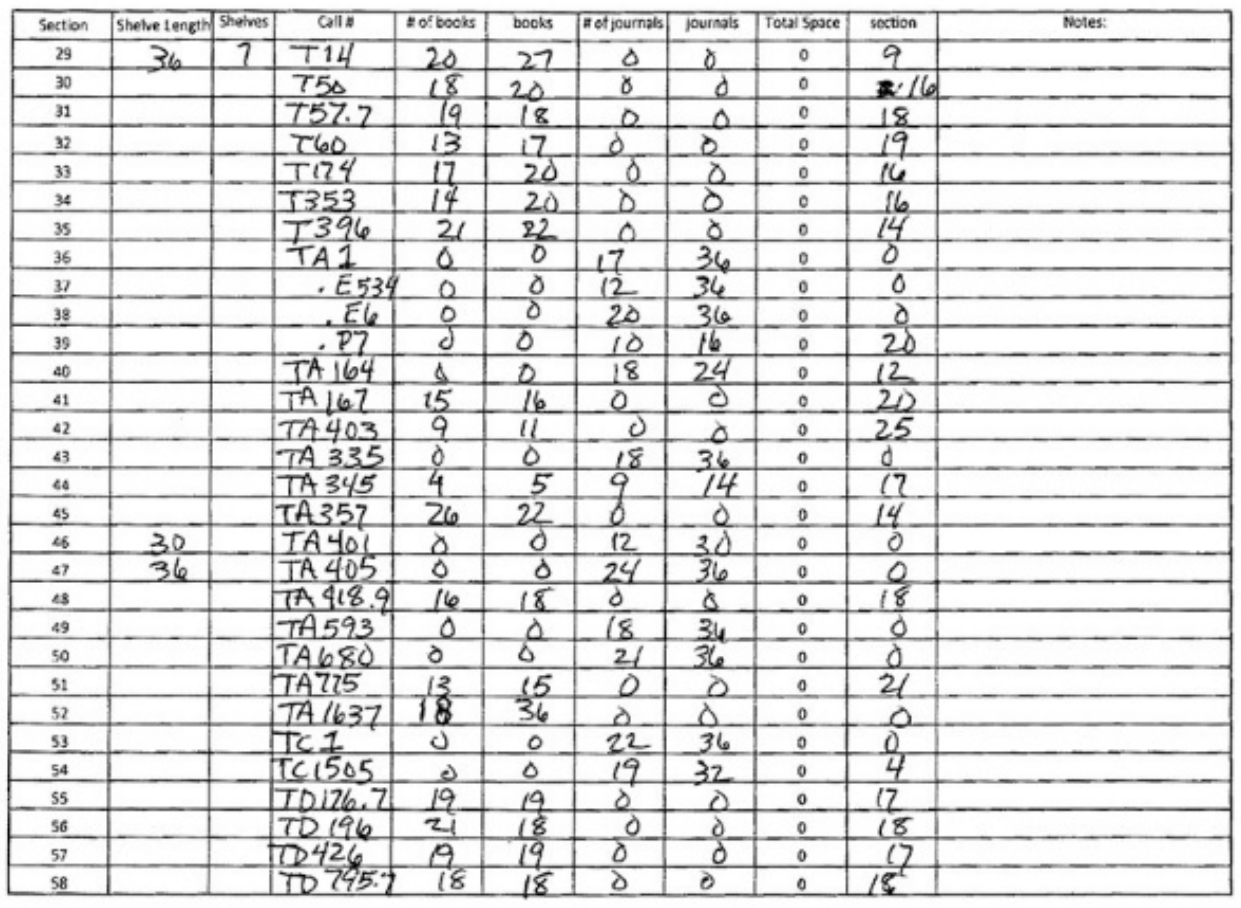

Figure 2. Sample data recorded manually from T call number class.

Calculations were performed to display data two different ways-by call number class and by block. The calculations displaying results by block are especially useful for those who are actually shifting materials. Stacks space earmarked for renovation does not overlay neatly with ranges containing an entire call number class. Rather, ranges are removed because of their physical location. For those planning and executing a shift of the collection, the ability to view the collections in terms of physical location is more important and more useful than knowing the size of the collection in specific subject areas.

Results displayed by call number class is of primary interest to subject librarians who are tasked with making decisions about collection management. Because the percentage of any given class occupied by books and journals varies among disciplines (or classification areas), and the withdrawal of journals in some classes will result in considerably more empty space than in other areas, the ability to

This is an electronic version of the following article: Weare, W. H., Jr., Moffett, P., \& Cooper, J. P. (2016). Preparing for renovation: Estimating shelf occupancy to inform decision making regarding the redevelopment of library space. Collection Management, 41(3), 168-181. Collection Management is available online at: http://tandfonline.com/toc/wcol20/41/3?nav=tocList. 
conceptualize the space (laid out by class) occupied by these materials can aid decisions about collection growth and weeding.

\section{Calculating the estimates: Empty space and occupied space}

The process for calculating percentage estimates for books, journals, and empty space uses the same mathematical operation. We began by calculating the percentage of empty space in each class. We divided the total actual amount of inches of empty space on the sample shelves by the total number of inches on the sample shelves. This yielded the percentage amount of empty space in that particular class. For example, in the "F" call number class the sum of empty inches from the column labeled "Empty" was 236 inches (see Figure 3). This number was divided by the total amount from the column labeled "Shelf Length" -642 inches-and the resulting figure gave the estimated percentage amount of empty space in " $\mathrm{F}$," in this case $37 \%$. Note that this process was applied to a call number class; we also repeated this calculation using the same data, grouped by block.

\begin{tabular}{|c|c|c|c|c|c|c|c|c|} 
Section & Shelve Length & Shelves & Call Number & \# of Books & $\begin{array}{c}\text { Inches of } \\
\text { Books }\end{array}$ & \# of Journals & $\begin{array}{c}\text { Inches of } \\
\text { Journals }\end{array}$ & $\begin{array}{c}\text { Empty Space } \\
\text { per Shelf }\end{array}$ \\
\hline 1 & 36 & 7 & F73.36 & 19 & 20 & 0 & 0 & 16 \\
\hline 2 & 36 & 7 & F129 & 21 & 16 & 12 & 4 & 16 \\
\hline 3 & 30 & 7 & F209 & 16 & 17 & 0 & 0 & 13 \\
\hline 4 & 36 & 7 & F251 & 0 & 0 & 13 & 25 & 11 \\
\hline 5 & 36 & 7 & F354 & 21 & 18 & 0 & 0 & 18 \\
\hline 6 & 30 & 7 & F474 & 17 & 17 & 0 & 0 & 13 \\
\hline 7 & 36 & 7 & F526 & 12 & 9 & 4 & 6 & 21 \\
\hline 8 & 36 & 7 & F548.5 & 20 & 21 & 0 & 0 & 15 \\
\hline 9 & 30 & 7 & F592.4 & 0 & 0 & 11 & 18 & 12 \\
\hline 10 & 36 & 7 & F786 & 15 & 14 & 3 & 5 & 17 \\
\hline 11 & 36 & 7 & F866 & 18 & 20 & 0 & 0 & 16 \\
\hline 12 & 30 & 7 & F1033 & 12 & 13 & 5 & 12 & 5 \\
\hline 13 & 36 & 7 & F1219.76 & 27 & 25 & 0 & 0 & 11 \\
\hline 14 & 36 & 7 & F1401 & 0 & 0 & 16 & 36 & 0 \\
\hline 15 & 30 & 7 & F1409.8 & 16 & 15 & 0 & 0 & 15 \\
\hline 16 & 30 & 7 & F1435.3 & 29 & 23 & 0 & 0 & 7 \\
\hline 17 & 36 & 7 & F2097 & 30 & 31 & 0 & 0 & 5 \\
\hline 18 & 30 & 7 & F2538.2 & 16 & 18 & 0 & 0 & 12 \\
\hline 19 & 36 & 7 & F3442 & 23 & 23 & 0 & 0 & 13 \\
\hline 19 & 642 & 133 & & 312 & 300 & 64 & 106 & 236 \\
\hline
\end{tabular}

This is an electronic version of the following article: Weare, W. H., Jr., Moffett, P., \& Cooper, J. P. (2016). Preparing for renovation: Estimating shelf occupancy to inform decision making regarding the redevelopment of library space. Collection Management, 41(3), 168-181. Collection Management is available online at: http://tandfonline.com/toc/wcol20/41/3?nav=tocList. 
Figure 3. Data collection sheet for F call number class.

Calculating occupied space is similar to the operation used to arrive at the amount of empty space, the difference being that the measurements of the sample shelves for space occupied by books and space occupied by journals must first be added together. Alternatively, one could simply subtract the percentage of empty space from the total to arrive at the percentage of occupied shelf space.

\section{Further calculations: Books and journals}

Regarding the calculations needed to determine the percentages occupied by books or journals, there are two separate possibilities. The first option would be to calculate percentage in relation to the whole shelf. For example, if a 36 -inch shelf contains 18 inches of books and 9 inches of journals, $50 \%$ of the shelf is occupied by books and $25 \%$ by journals. Hence, $25 \%$ of the shelf is empty. This first calculation would be useful if we are interested in potential available shelf space. If we were to consider relocating or withdrawing print indexes and journals, we would want to know how much space is potentially available. Thus, if $25 \%$ of the shelf space is occupied by journals and $25 \%$ of the shelf space is empty, then $50 \%$ of the space is available-if those journals are relocated or withdrawn.

The second option would be to calculate the percentage of only that portion of the shelf that is occupied by print materials. In this case, empty space is not included. Thus, if the same shelf as above has 18 inches of books and 9 inches of journals, then $66 \%$ of the items on that shelf are books and $33 \%$ are journals. This second calculation (percentage of only that portion of the shelf that is occupied) could be useful to a subject liaison who wanted to know what percentage of a particular class comprises books and what percentage comprises journals. Determining the ratio of books to periodicals in a particular class could also be met by generating a holdings report by material type.

\section{Checking for accuracy}

This is an electronic version of the following article: Weare, W. H., Jr., Moffett, P., \& Cooper, J. P. (2016). Preparing for renovation: Estimating shelf occupancy to inform decision making regarding the redevelopment of library space. Collection Management, 41(3), 168-181. Collection Management is available online at: 
To evaluate the accuracy of our use of systematic random sampling, we tested it in one call number class before applying it to the whole collection. This evaluation only sought to test the accuracy of the estimates of occupied space vs. empty space. We did not attempt to assess the accuracy of the estimate of books to journals because the ratio would vary by call number class. Every shelf in the "E" class was measured, and then those measurements were compared with the data from the sample. The total measurement of empty space in the " $E$ " class was 12,623 inches (of 38,826 ), or $32.5 \%$, while the sample data indicated that $37.5 \%$ of the space in that class was empty. Although a difference of this degree between the actual measurement and the sample data may not be satisfactory for every library, we deemed it acceptable for the scope of our project.

In addition to the disparity that occurred in our test, we also found other issues noted in the literature that can affect measurement. For example, Smith (1990) noted that compression of stock can affect measurements. There is of course a natural desire to tidy each shelve prior to measuring it; tidying could include squeezing the books on each shelf to the left, resulting in compression. Doing so would inflate the measurement of empty space. Smith also noted that items currently in use or out on loan would produce inaccuracies in the final measurements. We determined that issues such as these would not affect our overall measurements to a degree that would cause us concern because University Library does not have a space problem. Some level of imprecision would not impact our overall confidence in the estimates provided to the dean. As noted previously, the library has relatively few remaining print journal subscriptions. Although the library continues to add print monographs, increasingly e-books are purchased instead. We were primarily concerned with how much stacks space would be available for other uses - rather than collection growth and the potential to run out of space. We did not concern ourselves with absolute capacity as the library has ample space for collection growth.

This is an electronic version of the following article: Weare, W. H., Jr., Moffett, P., \& Cooper, J. P. (2016). Preparing for renovation: Estimating shelf occupancy to inform decision making regarding the redevelopment of library space. Collection Management, 41(3), 168-181. Collection Management is available online at: http://tandfonline.com/toc/wcol20/41/3?nav=tocList. 


\section{Results}

The results confirmed that the stacks contained a significant amount of unused shelf space. We estimated that approximately $33 \%$ of the shelf space was empty, $41 \%$ was occupied by books, and $26 \%$ was occupied by journals (see Figure 4). For call number classes B through $P$, we estimated that approximately $35 \%$ of the shelf space was empty, $48 \%$ was occupied by books, and $17 \%$ was occupied by journals. For call number classes $Q$ through $V, 27 \%$ was empty, $27 \%$ was occupied by books, and $46 \%$ was occupied by journals (see Appendix). The differences of percentages between books and journals was not surprising; as expected, more space was occupied by journals in classes $Q$ through $V$ than in the classes comprising social sciences and humanities.

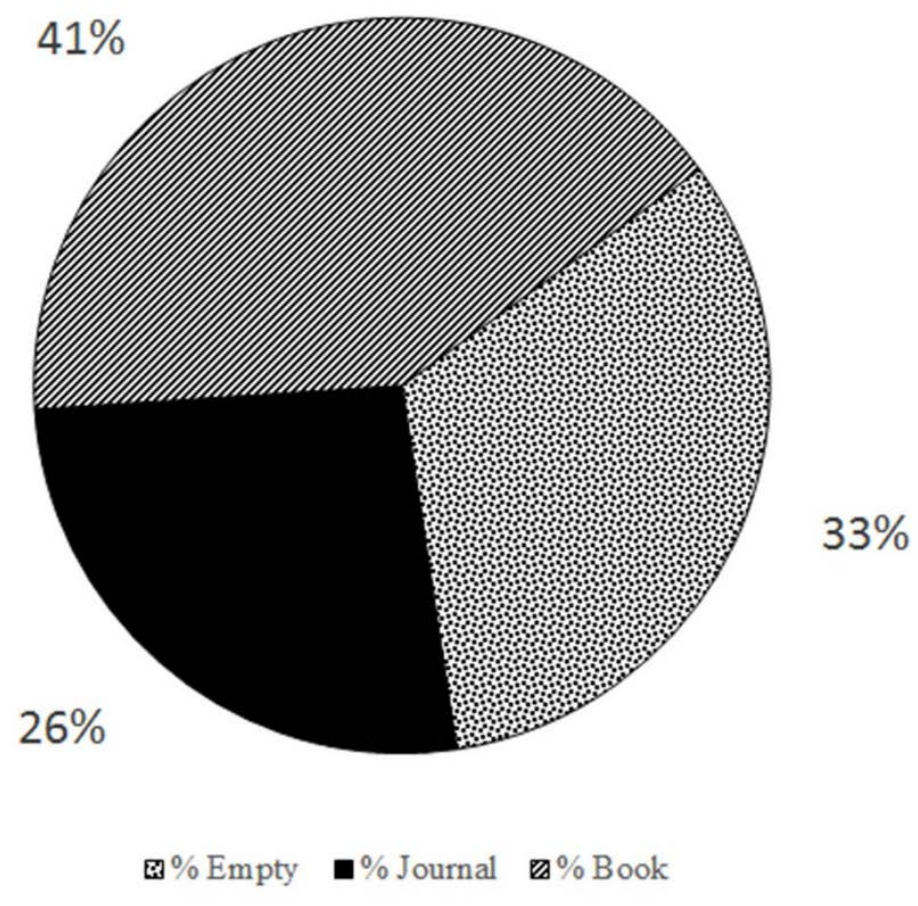

Figure 4. Estimates, general collection (classes B-V).

Our estimates provided us with the ability to report several key findings to the administrative team. First, we were able to confirm that there is ample space available to accommodate small-scale for renovation: Estimating shelf occupancy to inform decision making regarding the redevelopment of library space. Collection Management, 41(3), 168-181. Collection Management is available online at: 
renovation projects. Second-and more important- we would be able to report with precision the locations in the stacks where empty space is currently concentrated. Third, the estimates indicated that large amounts of additional space could be made available if print journals were withdrawn. For the study, a summary of results by call number is displayed in the Appendix.

\section{Conclusions}

Use of library space has evolved in recent years as a result of three significant changes in higher education: the shift from print to digital access, changes in the types of learning activities used to engage students, and the development of collaborative relationships between libraries and other academic units on campus. It is now apparent that new uses for physical space are preferable alternatives to housing seldom-used print materials.

As a preparatory step toward repurposing space, it is useful to determine how much space the present collection occupies and thus how much space may be available to accommodate new uses for that particular space. The method that we outlined is very simple compared with others found in the literature. The measurement process can be accomplished with minimal staff and time. The results can provide valuable and useful insight for access services staff, subject liaisons, and library administrators, aiding their ability to make informed decisions regarding renovation. The relatively simple, quick, and efficient data-gathering process described here, as well as data analysis and application, may be applicable in other academic libraries.

\section{Acknowledgments}

We would like to thank David Lewis, dean, IUPUI University Library, for suggesting that we apply a sampling approach to the measurement project described herein. We would also like to thank Lisa Calvert, Mindy Cooper, Matt Hinsman, and Matt Radican, our IUPUI University Library colleagues who provided valuable assistance.

This is an electronic version of the following article: Weare, W. H., Jr., Moffett, P., \& Cooper, J. P. (2016). Preparing for renovation: Estimating shelf occupancy to inform decision making regarding the redevelopment of library space. Collection Management, 41(3), 168-181. Collection Management is available online at: 


\section{References}

Allan, Colin. 2013. "Thinking Inside the Box." In Better Library and Learning Space: Projects, Trends and Ideas, edited by Les Watson, 159-65. London: Facet Publishing.

Babits, Ann, and Kurt Grice. 1987. "Microcomputers in Shelf Space Management." Microcomputers for Information Management 4 (2): 139-51.

Balmforth, C. K. 1973. "Measuring a Library: A Quantity Surveyor's Approach." In The Art of the Librarian: A Collection of Original Papers From the Library of the University of Newcastle Upon Tyne, edited by Alan Jeffreys, 33-57. Newcastle upon Tyne, England: Oriel Press.

Beck, Susan, E., and Kate Manuel. 2008. Practical Research Methods for Librarians and Information Professionals. New York: Neal-Schuman.

Bulpitt, Graham. 2013. "Powered by Learning: Developing Models of Provision to Meet the Expectations of New Generations of Students." In Better Library and Learning Space: Projects, Trends and Ideas, edited by Les Watson, 201-8. London: Facet Publishing.

Case, Jackie L., and Marion Thorp Ingram. 2006. "Stacks Management: An Organic Approach to Growing Space." Journal of Access Services 4 (3-4): 137-52. doi:10.1300/J204v04n03_11.

Castro, Rodrigo C. 2011. "Developing Tools to Calculate Space Availability, Establish Collection Distribution, and Determine Growth Rates: A Case Study." Technical Services Quarterly 28: 40618. doi:10.1080/07317131.2011.597691.

Cooper, Mindy M. 2011. “A Snapshot of a Print Journal Collection.” Indiana Libraries 30 (2): 42-5.

Cooper, Ruth, and David Norris. 2007. "To Bin or Not to Bin? Deselecting Print Back-Runs Available Electronically at Imperial College London Library." Serials 20 (3): 208-14.

Daehn, Ralph M. 1982. "The measurement and projection of shelf space." Collection Management 4 (4): 25-40.

Davis, Marlys Cresap. 1987. "Reutilizing Existing Library Space.” Library Trends 36 (2): 411-21.

Desroches, Richard A., and Marie Rudd. 1983. "Shelf Space Management: A Microcomputer Application." Information Technology and Libraries 2 (2): 187-9.

Dewey, Barbara I. 2008. "Social, Intellectual, and Cultural Spaces: Creating Compelling Library Environments for the Digital Age." Journal of Library Administration 48 (1): 85-94. doi:10.1080/01930820802035059.

Gayton, Jeffrey T. 2008. “Academic Libraries: 'Social' or 'Communal?' The Nature and Future of

This is an electronic version of the following article: Weare, W. H., Jr., Moffett, P., \& Cooper, J. P. (2016). Preparing for renovation: Estimating shelf occupancy to inform decision making regarding the redevelopment of library space. Collection Management, 41(3), 168-181. Collection Management is available online at: 
Academic Libraries." Journal of Academic Librarianship 34 (1): 60-6.

doi:10.1016/j.acalib.2007.11.011.

Griffin, Joanne, and Frances Foret. 2011. "Reducing Journal Stacks: How Tufts University's Hirsch Health Sciences Library Made Electronic Journals Work for Them." Serials Librarian 61 (3-4): 430-8. doi:10.1080/0361526X.2011.591178.

Gyeszly, Suzanne D., Marifran Bustion, and Jane Treadwell. 1990. "Infrequently Used Serials: A Space Utilization Project." Collection Management 12 (1/2): 109-23. doi:10.1300/J105v12n01_13.

Kaplan, Richard, Marilyn Steinberg, and Joanne Doucette. 2006. "Retention of Retrospective Print Journals in the Digital Age: Trends and Analysis." Journal of the Medical Library Association 94 (4): 387-93.

Lewis, David W. 2007. "A Strategy for Academic Libraries in the First Quarter of the 21st Century." College \& Research Libraries 68 (5): 418-34.

- - 2013. "From Stacks to the Web: The Transformation of Academic Library Collecting." College \& Research Libraries 74 (2): 159-76.

Maxymuk, John. 2010. "Library as a Place in Space." The Bottom Line: Managing Library Finances 23 (3): 128-31. doi:10.1108/08880451011087702.

Montanelli, Dale S. 1987. “Space Management for Libraries.” Illinois Libraries 69 (2): 130-8.

Moreland, Rachel S. 1987. "Managing Library Stacks Space with a Microcomputer." Small Computers in Libraries 7 (6): 38-41.

Peacock, P. G. 1983. "Measuring a Library." Aslib Proceedings 35 (3): 152-5.

- - . 1985. "The Management of Shelf Space." VINE: Very Informal Newsletter on Library Automation 15 (1): 39-42.

Persily, Gail L., and Karen A. Butter. 2010. "Reinvisioning and Redesigning 'a Library for the Fifteenth Through Twenty-First Centuries': A Case Study on Loss of Space From the Library and Center for Knowledge Management, University of California, San Francisco." Journal of the Medical Library Association (JMLA) 98 (1): 44-8. doi:10.3163/1536-5050.98.1.015.

Robinson, Cynthia K. 2009. "Library Space in the Digital Age: The Pressure Is On." The Bottom Line: Managing Library Finances 22 (1): 5-8. doi:10.1108/08880450910955369.

Sapp, Gregg, and George Suttle. 1994. "A Method for Measuring Collection Expansion Rates and Shelf Space Capacities." Journal of Academic Librarianship 20 (3): 156-61. doi:10.1016/00991333(94)90009-4.

Sharp, Steven. 2009. "No More Room Aboard the Ark! A UK Higher Education Perspective on Space

This is an electronic version of the following article: Weare, W. H., Jr., Moffett, P., \& Cooper, J. P. (2016). Preparing for renovation: Estimating shelf occupancy to inform decision making regarding the redevelopment of library space. Collection Management, 41(3), 168-181. Collection Management is available online at:

http://tandfonline.com/toc/wcol20/41/3?nav=tocList. 
Management." Interlending \& Document Supply 37 (3): 126-31.

doi:10.1108/02641610910985585.

Simon, Matthew. 2013. "US Projects and Trends." In Better Library and Learning Space: Projects, Trends and Ideas, edited by Les Watson, 22-36. London: Facet Publishing.

Smith, Debbi A. 2007. "Creating Stack Floor Plans and Signage: Excel as a Collection Management Tool." Technical Services Quarterly 24 (3): 29-39. doi:10.1300/J124v24n03_03.

Smith, N. R. 1990. "A Shelf-Management Model Implemented on Multiplan." Information Technology and Libraries 9 (1): 66-73.

Thomas, William Joseph, and Daniel L. Shouse. 2012. "Rules of Thumb for Deselecting, Relocating, and Retaining Bound Journals." Collection Building 31 (3): 92-7. doi:10.1108/01604951211243470.

Wallace, Patricia M. 1990. "Predicting Future Shelving Needs." Collection Management 12 (1/2): 95-107. doi:10.1300/J105v12n01_12.

This is an electronic version of the following article: Weare, W. H., Jr., Moffett, P., \& Cooper, J. P. (2016). Preparing for renovation: Estimating shelf occupancy to inform decision making regarding the redevelopment of library space. Collection Management, 41(3), 168-181. Collection Management is available online at: http://tandfonline.com/toc/wcol20/41/3?nav=tocList. 


\section{Appendix: Estimates}

The figures that follow display estimates of shelf occupancy at IUPUI University Library.

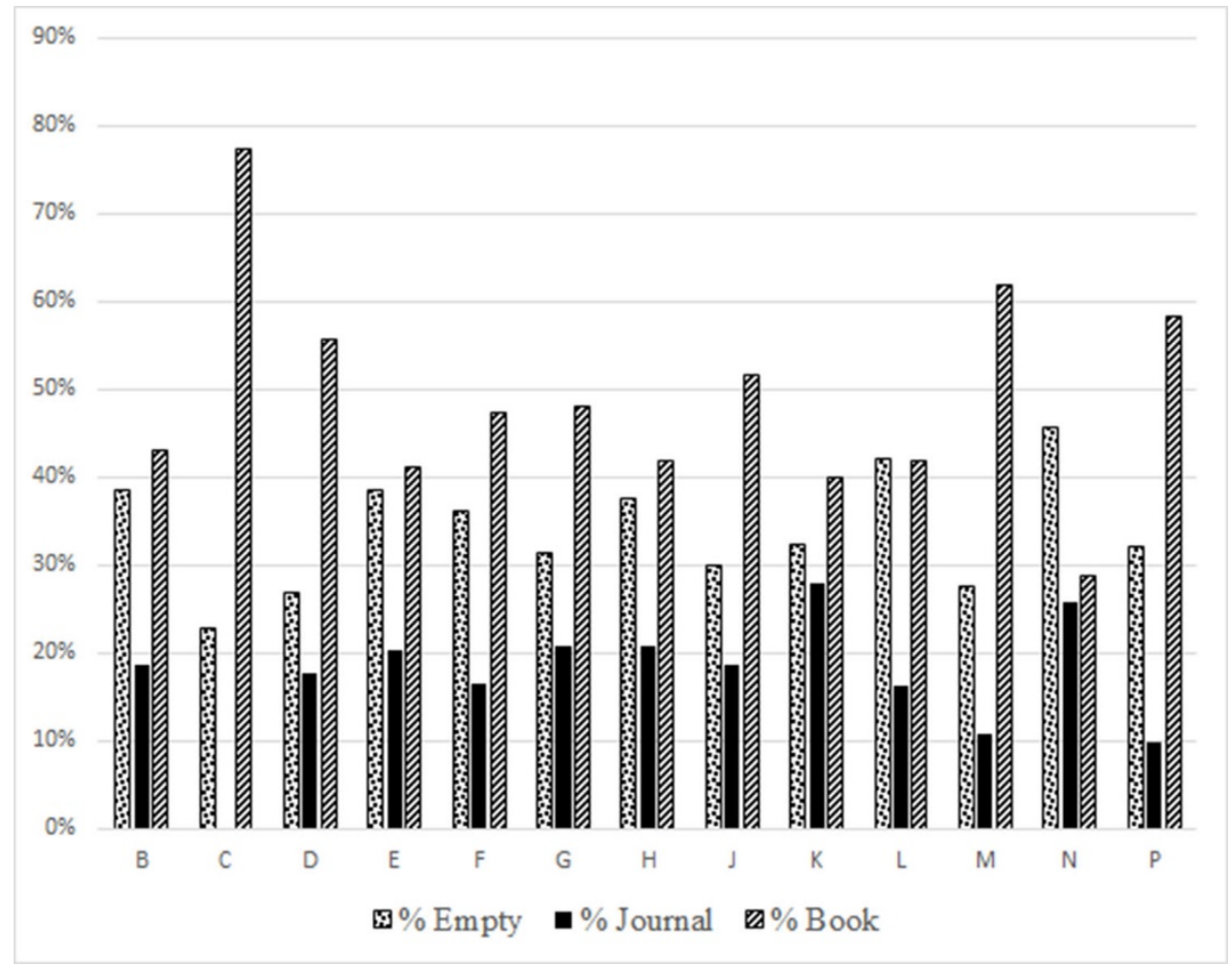

Figure A1. Estimates by call number, B-P.

This is an electronic version of the following article: Weare, W. H., Jr., Moffett, P., \& Cooper, J. P. (2016). Preparing for renovation: Estimating shelf occupancy to inform decision making regarding the redevelopment of library space. Collection Management, 41(3), 168-181. Collection Management is available online at: http://tandfonline.com/toc/wcol20/41/3?nav=tocList. 


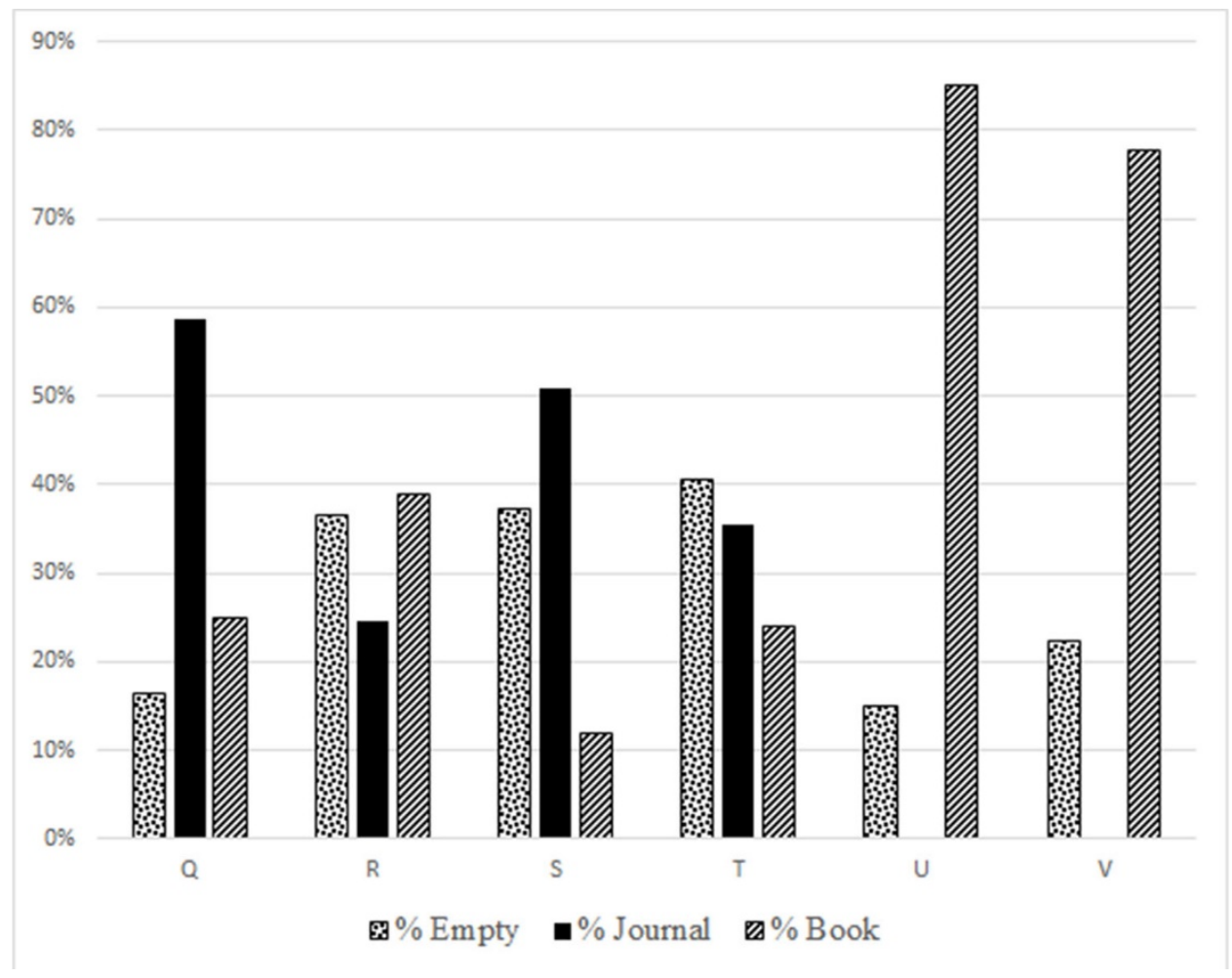

Figure A2. Estimates by call number, Q-V.

This is an electronic version of the following article: Weare, W. H., Jr., Moffett, P., \& Cooper, J. P. (2016). Preparing for renovation: Estimating shelf occupancy to inform decision making regarding the redevelopment of library space. Collection Management, 41(3), 168-181. Collection Management is available online at: http://tandfonline.com/toc/wcol20/41/3?nav=tocList. 